Article

\title{
An Effective Method to Remove Antimony in Water by Using Iron-Based Coagulants
}

\author{
Kuan Cheng, Hongtao Wang, Jie Li and Fengting Li *
}

State Key Laboratory of Pollution Control and Resource Reuse, College of Environmental Science and Engineering, Tongji University, Siping Rd 1239, Shanghai 200092, China; kuanchengtongji@163.com (K.C.); hongtao@tongji.edu.cn (H.W.); lijie2012tj@163.com (J.L.)

* Correspondence: fengting@tongji.edu.cn

Received: 9 November 2019; Accepted: 20 December 2019; Published: 23 December 2019

\begin{abstract}
The effectiveness of antimony $(\mathrm{Sb})$ removal by using iron-based coagulants was investigated in this study. The effects of $\mathrm{pH}$, coagulant types and dose, equilibrium concentration, co-existing humic acid (HA) and anions, and oxidation process were studied. Effective $\mathrm{Sb}$ removal was achieved by using $\mathrm{Fe}(\mathrm{III})$-based coagulants. However, the removal efficiency of Sb by using Fe(II)-based coagulants was very low. The removal capacity of $\mathrm{Sb}$ fitted the Sips adsorption isotherm well, which revealed that the heterogeneous adsorption process onto the formed hydrous ferric oxide played an important role in Sb removal, and the mechanism was further supported by Fourier transform infrared spectrum analysis. Sb removal was inhibited by the presence of HA and phosphate, as well as oxidation and aeration. Therefore, coagulation by using Fe(III)-based coagulants without oxidation is an effective and promising method for removing $\mathrm{Sb}$ in aqueous solution.
\end{abstract}

Keywords: antimony removal; iron-based coagulant; polymeric ferric sulfate; oxidation

\section{Introduction}

Increasing antimony $(\mathrm{Sb})$ contaminations pose a great threat to the environment and human beings, and have attracted increasing attention worldwide [1]. Besides natural activities, human activities, especially mining, dying, and textile industries, have aggravated the pollution and spread of $\mathrm{Sb} . \mathrm{Sb}$ is highly toxic to human health, causing damage to the skin, eyes, lungs, stomach, liver, kidneys, heart, and nervous system [2]. Sb has been declared a high-priority pollutant of interest by the United States Environmental Protection Agency (USEPA) and European Union (EU). The maximum allowable concentration of $\mathrm{Sb}$ in water is regulated as 6,10 , and $5 \mu \mathrm{g} \cdot \mathrm{L}^{-1}$ by the USEPA, EU, and the World Health Organization (WHO), respectively [3-5].

Given the high toxicity and severe pollution of $\mathrm{Sb}$, many technologies have been developed to remove $\mathrm{Sb}$ from water in recent years, such as coagulation [6,7], adsorption [8,9], membrane [10], and electro-coagulation [11] related technologies. For example, many adsorbents were applied to remove $\mathrm{Sb}$, such as goethite, diatomite, and Fe-Mn binary oxide [12]. Peatlands and constructed wetlands were investigated in regard to the removal of $\mathrm{Sb}$ from mining waste water via adsorption processes $[13,14]$. Among the developed technologies, the coagulation method remains popular worldwide due to its low cost, high efficiency, simple design and operation, and good matching with other water treatment equipment $[15,16]$. In addition, coagulation can achieve in situ removal of $\mathrm{Sb}$ in the case of emergency pollution incidents. Sb removal by coagulation with iron salts and aluminum salts was investigated, and the results revealed that ferric chloride (FC) exhibited better performance than poly-aluminum chloride for $\mathrm{Sb}$ removal, indicating that iron-based coagulants exhibited good performance in $\mathrm{Sb}$ removal [17]. Additionally, iron-based coagulants were demonstrated to exhibit good performance in $\mathrm{Sb}$ removal. The adsorption of formed hydrous ferric oxide (HFO) was found 
to play an important role in Sb removal $[18,19]$. However, the performance of different iron-based coagulants for $\mathrm{Sb}$ removal, such as polymeric ferric sulfate (PFS), FC, and ferrous sulfate $\left(\mathrm{FeSO}_{4}\right)$, still remains to be explored.

$\mathrm{Sb}$ is a metalloid, the fourth element of Group VA in the periodic table. Given its natural and anthropogenic activities, $\mathrm{Sb}$ has been found in soil and water environments. $\mathrm{Sb}(\mathrm{III})$ and $\mathrm{Sb}(\mathrm{V})$ are the predominant states of $\mathrm{Sb}$ that exist in aerobic environments [20-22]. Under mildly acidic, neutral, and alkaline conditions, $\mathrm{Sb}(\mathrm{OH})_{3}$ and $\mathrm{Sb}(\mathrm{OH})_{6}{ }^{-}$are the dominant species for $\mathrm{Sb}(\mathrm{III})$ and $\mathrm{Sb}(\mathrm{V})$, respectively. $\mathrm{Sb}(\mathrm{III})$ is more toxic than $\mathrm{Sb}(\mathrm{V})$, but the solubility of the latter is higher than that of the former [2]. Guo et al. found that $\mathrm{Sb}(\mathrm{III})$ was easier to remove by coagulation with FC than $\mathrm{Sb}(\mathrm{V})$ [18]. In natural aqueous environments, many co-existing matters, including competing ions and organic matters, could interfere with the removal of $\mathrm{Sb}$ by coagulation. Moreover, the oxidization process can affect the state and removal of $\mathrm{Sb}$ in water by coagulation [23]. For example, the addition of $\mathrm{KMnO}_{4}$ and aeration process, the common water treatment process, can oxidize $\mathrm{Sb}(\mathrm{III})$ to $\mathrm{Sb}(\mathrm{V})$ [24,25].

In the present work, the effects of solution $\mathrm{pH}$, coagulant types, and dose on the removal of $\mathrm{Sb}$ by $\mathrm{Fe}(\mathrm{III})$ - and Fe(II)-based coagulants were investigated. In addition, the effects of competing matters, as well as oxidation, for $\mathrm{Sb}$ removal by coagulation were explored. The adsorption isotherms and mechanisms were also studied.

\section{Materials and Methods}

\subsection{Reagents}

Potassium pyroantimonate $\left(\mathrm{K}_{2} \mathrm{H}_{2} \mathrm{Sb}_{2} \mathrm{O}_{7} \cdot 4 \mathrm{H}_{2} \mathrm{O}\right)$, L-antimony potassium tartrate $\left(\mathrm{C}_{8} \mathrm{H}_{4} \mathrm{~K}_{2} \mathrm{O}_{12} \mathrm{Sb}_{2}\right)$, hydrochloric acid $(\mathrm{HCl})$, sodium hydroxide $(\mathrm{NaOH})$, ferrous sulfate $\left(\mathrm{FeSO}_{4} \cdot 7 \mathrm{H}_{2} \mathrm{O}\right), \mathrm{FC}\left(\mathrm{FeCl}_{3} \cdot 6 \mathrm{H}_{2} \mathrm{O}\right)$, and potassium permanganate $\left(\mathrm{KMnO}_{4}\right)$ were analytical grade reagents. $\mathrm{FeSO}_{4} \cdot 7 \mathrm{H}_{2} \mathrm{O}, \mathrm{FeCl}_{3} \cdot 6 \mathrm{H}_{2} \mathrm{O}$, and PFS $\left(\left[\mathrm{Fe}_{2}(\mathrm{OH})_{\mathrm{n}}\left(\mathrm{SO}_{4}\right)_{3-\mathrm{n} / 2}\right]_{\mathrm{m}}\right)$ were used as coagulants in this work. All chemical agents in the experiments were purchased from (Sinopharm Chemical Reagent Co., Ltd., Shanghai, China). $\mathrm{Sb}(\mathrm{V})$ and $\mathrm{Sb}(\mathrm{III})$ stock solutions were prepared from potassium pyroantimonate $\left(\mathrm{K}_{2} \mathrm{H}_{2} \mathrm{Sb}_{2} \mathrm{O}_{7} \cdot 4 \mathrm{H}_{2} \mathrm{O}\right)$ and L-antimony potassium tartrate $\left(\mathrm{C}_{8} \mathrm{H}_{4} \mathrm{~K}_{2} \mathrm{O}_{12} \mathrm{Sb}_{2}\right)$ in water.

\subsection{Coagulation Procedure}

\subsubsection{Instrumental Analysis}

The $\mathrm{Sb}$ concentration in water was measured by inductively coupled plasma mass spectrometry (ICP-MS) (iCAP RQ ICP-MS, (Thermo Fisher Scientific Inc., Waltham, MA USA)) to evaluate the efficiency of coagulation. The $\mathrm{pH}$ was measured with a $\mathrm{pH}$ electrode (PHB-3 pH Pocket Tester, Shanghai San-Xin Instrumentation Inc. Shanghai, China). Fourier transform infrared (FTIR) spectrum were obtained in the range of 4000 to $400 \mathrm{~cm}^{-1}$ on a Thermo Scientific Nicolet IS10 using KBr pellets (Thermo Fisher Scientific Inc., Waltham, MA USA). The zeta potential was measured by Zeta potential analyzer (Zetasizer Nano ZS 90, Malvern Panalytical Ltd., Malvern, UK).

\subsubsection{Batch Experiments}

PFS, FC, and $\mathrm{FeSO}_{4}$ were selected as coagulants for $\mathrm{Sb}$ removal, and the coagulant concentration was calculated as Fe. Sb samples were prepared by diluting Sb stock solution into water to obtain $\mathrm{Sb}$ synthetic aqueous samples of $\mathrm{Sb}(\mathrm{III})$ or $\mathrm{Sb}(\mathrm{V})$. Coagulation experiments were performed with jar tests at room temperature $\left(\sim 20^{\circ} \mathrm{C}\right)$. The coagulation experiments were rapidly stirred at $200 \mathrm{rpm}$ for $3 \mathrm{~min}$ and then slowly stirred at $40 \mathrm{rpm}$ for $20 \mathrm{~min}$, followed by settling down for $30 \mathrm{~min}$. Subsequently, the clear supernatants were collected and filtrated with a $0.22-\mu \mathrm{M}$ pore size membrane filter before analysis. The $\mathrm{pH}$ of each sample was adjusted with $0.1 \mathrm{M} \mathrm{HCl}$ or $0.1 \mathrm{M} \mathrm{NaOH}$. The experiments on the effects of $\mathrm{pH}$ and dosage were duplicated three times, and the average results are reorted in this paper. 
To determine the optimum $\mathrm{pH}$, the removal efficiencies of $\mathrm{Sb}(\mathrm{III})$ or $\mathrm{Sb}(\mathrm{V})$ (with initial Sbconcentration of about $200 \mu \mathrm{g} \cdot \mathrm{L}^{-1}$ ) were investigated by using Fe-based coagulants (dose of $10 \mathrm{mg} \cdot \mathrm{L}^{-1}$ as $\mathrm{Fe}$ ) at $\mathrm{pH}$ values ranging from 3 to 10 . At the optimum $\mathrm{pH}$, the $\mathrm{Sb}$ removal efficiencies of three coagulants (PFS, $\mathrm{FC}$, and $\mathrm{FeSO}_{4}$ ) were investigated at a coagulant dose of 5, 10, 15, 20, 30, and $40 \mathrm{mg} \cdot \mathrm{L}^{-1}$. The adsorption isotherm experiments of $\mathrm{Sb}(\mathrm{III})$ and $\mathrm{Sb}(\mathrm{V})$ were conducted with batch experiments at initial $\mathrm{Sb}$ loading in the range of $30 \mu \mathrm{g} \cdot \mathrm{L}^{-1}$ to $4 \mathrm{mg} \cdot \mathrm{L}^{-1}$ and with a coagulant dose of $10 \mathrm{mg} \cdot \mathrm{L}^{-1}$. To study the interference of co-existing substances in natural water, the effects of humic acid $\left(\mathrm{HA}, 2 \mathrm{mg} \cdot \mathrm{L}^{-1}\right)$ and competing ions ( $2 \mathrm{mmol} \cdot \mathrm{L}^{-1}$ ), including $\mathrm{Cl}^{-}, \mathrm{F}^{-}, \mathrm{NO}_{3}{ }^{-}, \mathrm{HCO}_{3}{ }^{-}, \mathrm{SO}_{4}{ }^{2-}$, and $\mathrm{PO}_{4}{ }^{3-}$, were investigated. Approximately 1,5 , and $10 \mathrm{mg} \cdot \mathrm{L}^{-1}$ of $\mathrm{KMnO}_{4}$ were applied to pre-oxidize samples prior to the coagulation process with $10 \mathrm{mg} \cdot \mathrm{L}^{-1}$ of PFS. In addition, the aeration process was conducted for 20, 40, and $60 \mathrm{~min}$ prior to coagulation with PFS to investigate the effect of oxidization.

The concept of adsorption capacity was applied to analyze the removal performance of iron coagulants. The adsorption capacity here referred to the amount of $\mathrm{Sb}$ removed per unit mass of iron coagulants.

$$
Q_{e}=\frac{\left(C_{0}-C_{e}\right) \times V}{M}
$$

where $Q_{e}\left(\mathrm{mg} \cdot \mathrm{g}^{-1}\right)$ is the amount of $\mathrm{Sb}$ adsorption capacity per unit of the coagulant, $C_{0}\left(\mathrm{mg} \cdot \mathrm{L}^{-1}\right)$ is the initial concentration of $\mathrm{Sb}, C_{e}\left(\mathrm{mg} \cdot \mathrm{L}^{-1}\right)$ is the equilibrium concentration of $\mathrm{Sb}$ after coagulation, $V(\mathrm{~L})$ is the volume of the solution, and $M(\mathrm{~g})$ is the amount of coagulants added in the experiments.

The adsorption behavior of Sb by HFO flocs in the coagulation was described with Freundlich and Sips isotherms. The Freundlich isotherm is presented by

$$
Q_{e}=K_{f} C_{e}^{\frac{1}{n}}
$$

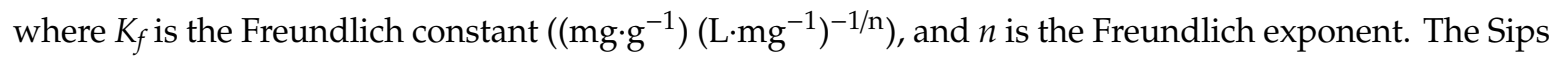
isotherm is derived from the Langmuir and Freundlich isotherms. The Sips adsorption isotherm is presented by

$$
Q_{e}=Q_{m} \frac{K_{s} C_{e}^{\gamma}}{1+K_{s} C_{e}^{\gamma}}
$$

where $Q_{m}\left(\mathrm{mg}^{-1}\right)$ is the maximum adsorption capacity calculated by the equation, $K_{S}$ is the Sips


of adsorbents.

\section{Results and Discussion}

\subsection{Effects of $p H$}

As shown in Figure 1a, 84\%, 88\%, and 15\% of $\mathrm{Sb}(\mathrm{III})$ was removed by PFS, FC, and $\mathrm{FeSO}_{4}$, respectively at a $\mathrm{pH}$ of 3 . When the $\mathrm{pH}$ was increased to 5 , the highest removal rates of $\mathrm{Sb}$ (III) by using PFS, FC, and $\mathrm{FeSO}_{4}$ were obtained (95\%, 94\%, and $60 \%$, respectively). The $\mathrm{Sb}$ (III) removal rate by using PFS and FC remained higher than $85 \%$ within a wide $\mathrm{pH}$ range of 3 to 9 . However, for $\mathrm{FeSO}_{4}$, the removal rate decreased remarkably when the $\mathrm{pH}$ was increased from 5 to 10 . As shown in Figure $1 \mathrm{~b}$, the highest removal rate of $\mathrm{Sb}(\mathrm{V})$ was $92 \%$ and $93 \%$ at $\mathrm{pH} 5$ with $\mathrm{PFS}$ and $\mathrm{FC}$, respectively, and $79 \%$ at $\mathrm{pH} 6$ with $\mathrm{FeSO}_{4}$. When the $\mathrm{pH}$ was increased from 3 to 5, the removal rate of $\mathrm{Sb}(\mathrm{V})$ increased slightly by using PFS and FC; however, a steep increase of the $\mathrm{Sb}(\mathrm{V})$ removal rate was obtained (4\% to $75 \%$ ) by using $\mathrm{FeSO}_{4}$. When the $\mathrm{pH}$ values increased from 5 to 6 , the removal rate of $\mathrm{Sb}(\mathrm{V})$ by using the three coagulants changed slightly. When the $\mathrm{pH}$ was further increased from 6 to 10, the removal rate of $\mathrm{Sb}(\mathrm{V})$ decreased to $12 \%, 15 \%$, and $7 \%$ for PFS, $\mathrm{FC}$, and $\mathrm{FeSO}_{4}$, respectively. The optimum $\mathrm{pH}$ value was set at $\mathrm{pH} 5$ for other batches. 

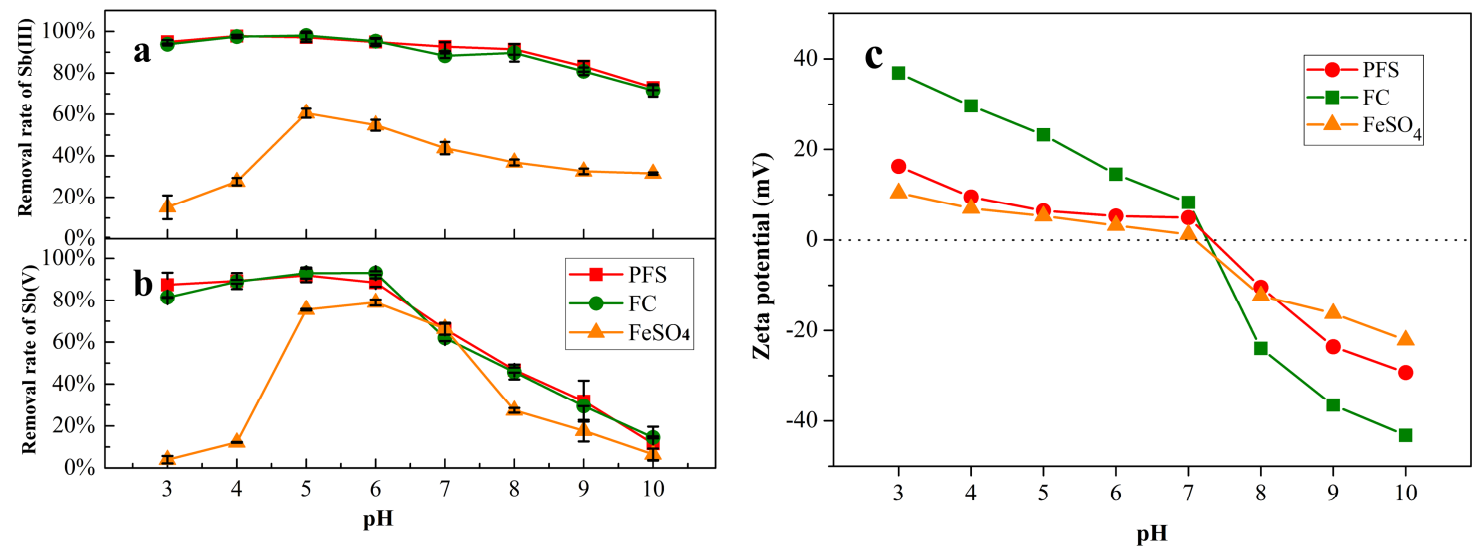

Figure 1. Effects of $\mathrm{pH}$ on (a) $\mathrm{Sb}(\mathrm{III})$ and (b) $\mathrm{Sb}(\mathrm{V})$ removal with $10 \mathrm{mg} \cdot \mathrm{L}^{-1}$ of $\mathrm{PFS}, \mathrm{FC}$, and $\mathrm{FeSO}_{4}$ (initial $\mathrm{Sb}(\mathrm{III})$ and $\mathrm{Sb}(\mathrm{V})$ concentrations: $200 \mu \mathrm{g} \cdot \mathrm{L}^{-1}$ ). (c) Zeta potential of PFS, FC, and $\mathrm{FeSO}_{4}\left(\mathrm{PFS}_{\mathrm{FC}}\right.$, and $\mathrm{FeSO}_{4}$ concentrations: $30 \mathrm{mg} \cdot \mathrm{L}^{-1}$ as $\mathrm{Fe}$ ). PFS: polymeric ferric sulfate; $\mathrm{FC}$ : ferric chloride.

Within a broad $\mathrm{pH}$ range of 3 to 9 , effective $\mathrm{Sb}(\mathrm{III})$ removal was obtained with PFS and FC. However, the optimum $\mathrm{pH}$ value for $\mathrm{Sb}(\mathrm{V})$ removal ranged from 5 to 6 . For $\mathrm{PFS}$ and $\mathrm{FC}$, the removal efficiency of $\mathrm{Sb}$ (III) was higher than that of $\mathrm{Sb}(\mathrm{V})$. However, for $\mathrm{FeSO}_{4}$, the removal efficiency of $\mathrm{Sb}$ (III) was lower than that of $\mathrm{Sb}(\mathrm{V})$. As the $\mathrm{pH}$ value increased, the zeta potential of $\mathrm{PFS}, \mathrm{FC}$, and $\mathrm{FeSO}_{4}$ decreased (Figure 1c). When the $\mathrm{pH}$ value was below 7 , the formed flocs was positively charged. When the iron-based coagulants were added into water at the optimum $\mathrm{pH}$ of $5, \mathrm{Fe}(\mathrm{III})$ ions were hydrolyzed to form HFO. During agitation, the positively charged HFO adsorbed the neutrally charged $\mathrm{Sb}$ (III) or negatively charged $\mathrm{Sb}(\mathrm{V})$, resulting in the electrical neutralization and compression of the electric double layer for colloids. As a result, the HFO colloid became unstable and larger HFO flocculates were formed, precipitated, and separated from water, achieving the removal of antimony. The electrostatic interaction between the positively charged flocs and negatively charged $\mathrm{Sb}(\mathrm{OH})_{6}{ }^{-}$promoted the removal of $\mathrm{Sb}(\mathrm{V})$. However, when the $\mathrm{pH}$ value was below 3, the hydrolysis of iron-based coagulants decreased, which inhibited the removal of $\mathrm{Sb}$.

In the coagulation process for Sb removal with iron-based coagulants, the active HFO flocs with many adsorption sites were formed due to the hydrolysis of iron ions in solution [10]. The $\mathrm{pH}$ value of the solution affected the properties of $\mathrm{HFO}$ flocs and the state of $\mathrm{Sb}$ in solution, which further affected the removal of $\mathrm{Sb}$ by coagulation. At $\mathrm{pH} 5, \mathrm{Fe}(\mathrm{OH})_{2}{ }^{+}$and $\mathrm{Fe}(\mathrm{OH})^{2+}$ were the predominant $\mathrm{Fe}(\mathrm{III})$ species other than $\mathrm{Fe}(\mathrm{OH})_{3}$. With the further increase of $\mathrm{pH}$, the cationic Fe species decreased, and anionic Fe species such as $\mathrm{Fe}(\mathrm{OH})_{4}{ }^{-}$increased [17]. In solution, $\mathrm{Sb}(\mathrm{V})$ existed as soluble anion $\mathrm{Sb}(\mathrm{OH})_{6}{ }^{-}$. The electrostatic interaction between $\mathrm{Sb}(\mathrm{OH})_{6}{ }^{-}$and $\mathrm{Fe}(\mathrm{III})$ species facilitated the combination of $\mathrm{HFO}-\mathrm{Sb}(\mathrm{V})$, which was affected by the $\mathrm{pH}$ value. Hence, the removal of $\mathrm{Sb}(\mathrm{V})$ by coagulation was affected. However, $\mathrm{Sb}$ (III) existed as a neutral molecule in water. The interaction between neutral $\mathrm{Sb}$ (III) and HFO flocs was due to chemical bonding, which was affected slightly by $\mathrm{pH}$ values of the solution. The low solubility of $\mathrm{Sb}$ (III) species facilitated $\mathrm{Sb}$ (III) removal [10]. Contrary to the effective $\mathrm{Sb}$ removal by using PFS and FC, the removal efficiency by using $\mathrm{FeSO}_{4}$ was relatively low. Although the removal efficiency of $\mathrm{Sb}(\mathrm{V})$ with $\mathrm{FeSO}_{4}$ was higher than that of $\mathrm{Sb}(\mathrm{III})$, it was still lower than that of $\mathrm{Sb}(\mathrm{V})$ with $\mathrm{Fe}(\mathrm{III})$-based coagulants.

\subsection{Effects of Coagulant Dose}

Figure 2 shows that as the coagulant concentration increased, the removal rates of $\mathrm{Sb}(\mathrm{III})$ and $\mathrm{Sb}(\mathrm{V})$ increased until equilibrium was reached. Both PFS and FC exhibited better removal performance for $\mathrm{Sb}$ than $\mathrm{FeSO}_{4}$. Approximately $20 \mathrm{mg} \cdot \mathrm{L}^{-1}$ of PFS and $\mathrm{FC}$ were required to reduce the concentration of $\mathrm{Sb}$ (III) below $5 \mu \mathrm{g} \cdot \mathrm{L}^{-1}$, in compliance with the WHO drinking water quality standard. Approximately $30 \mathrm{mg} \cdot \mathrm{L}^{-1}$ of PFS and FC were required to decrease the concentration of $\mathrm{Sb}(\mathrm{V})$ below $5 \mu \mathrm{g} \cdot \mathrm{L}^{-1}$, indicating 
that $\mathrm{Sb}(\mathrm{V})$ was more difficult to remove than $\mathrm{Sb}(\mathrm{III})$ by using PFS and FC. By coagulating with $\mathrm{FeSO}_{4}$, the remaining concentrations of $\mathrm{Sb}(\mathrm{III})$ and $\mathrm{Sb}(\mathrm{V})$ were higher than $5 \mu \mathrm{g} \cdot \mathrm{L}^{-1}$, which did not meet the standard.

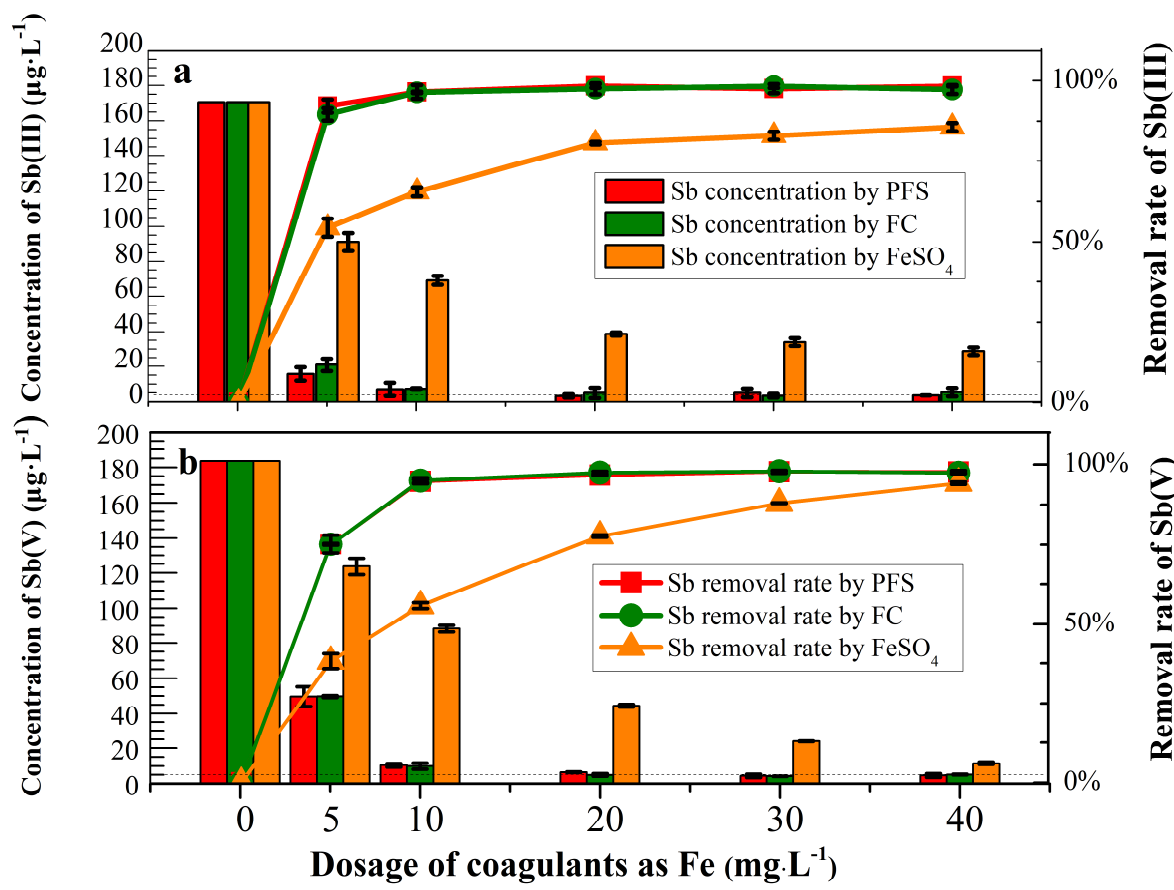

Figure 2. Effects of concentrations of coagulants on the removal of (a) $\mathrm{Sb}(\mathrm{III})$ and (b) $\mathrm{Sb}(\mathrm{V})$ by using PFS, FC, and $\mathrm{FeSO}_{4}$ respectively (initial concentration of $\mathrm{Sb}(\mathrm{III}): 176 \mu \mathrm{g} \cdot \mathrm{L}^{-1} ; \mathrm{Sb}(\mathrm{V}): 185 \mu \mathrm{g} \cdot \mathrm{L}^{-1}$ ).

Furthermore, $\mathrm{Sb}$ removal experiments were carried out using natural water obtained from Taihu Lake, Jiangsu Province, China (Figure S1). The Chemical Oxygen Demand (COD) in water was $42 \mathrm{mg} \cdot \mathrm{L}^{-1}$. PFS was applied to remove $\mathrm{Sb}$, and the initial concentrations of $\mathrm{Sb}(\mathrm{III})$ and $\mathrm{Sb}(\mathrm{V}) \mathrm{were}$ 104 and $116 \mu \mathrm{g} \cdot \mathrm{L}^{-1}$. Both $\mathrm{Sb}(\mathrm{III})$ and $\mathrm{Sb}(\mathrm{V})$ were effectively removed at the PFS dosage of $20 \mathrm{mg} \cdot \mathrm{L}^{-1}$, and the concentration of residual Sb was below $5 \mu \mathrm{g} \cdot \mathrm{L}^{-1}$, meeting the WHO drinking water standard.

After coagulation, there were possibly some iron ions left in the water. Most iron ions could be precipitated as $\mathrm{Fe}(\mathrm{OH})_{3}$ in neutral water or removed in the subsequent treatment steps. The low toxicity and biocompatibility of iron-based coagulants ensured the safety of the treated water.

For the practical emergency treatment of $\mathrm{Sb}$ pollution in a lake, there are two main ways of using coagulation, namely, in-situ emergency treatment and off-site emergency treatment. The in-situ treatment involves adding chemicals into the lake directly. The pollutants will be deposited along with the sediment at the bottom of the lake, but there is a risk that the sediments will possibly be stirred up again. The off-site treatment involves pumping lake water into a sewage treatment station or facility for treatment. The treated water can be discharged back into the lake. The resulting sludge can be separated through a sedimentation tank, and then tested, treated, or comprehensively utilized.

\subsection{Adsorption Isotherms}

Adsorption by the formed HFO flocs during the coagulation process was the main routine for $\mathrm{Sb}$ removal [18]. The adsorption isotherms were applied to describe the adsorption behavior of Sb by HFO flocs in the coagulation, including Langmuir, Freundlich, and Sips isotherms. The Langmuir isotherm illustrates the adsorption behavior of an ideal adsorption system with homogeneous surface of the adsorbent. However, the results of simulated data via Langmuir isotherm were unreasonable. The Freundlich isotherm explains heterogeneous adsorption behavior, which indicates that different adsorption energies exist in different surface sites [26]. The Sips isotherm is derived from the Langmuir 
and Freundlich isotherms. The result of adsorption capacity for Sb fitted well with the Sips adsorption isotherm. All the parameters of equations, as shown in Table 1, were derived from the nonlinear least-squares regression of the experimental data.

Table 1. Constants of Freundlich and Sips isotherms for $\mathrm{Sb}(\mathrm{III})$ and $\mathrm{Sb}(\mathrm{V})$ adsorption on hydrous ferric oxide flocs.

\begin{tabular}{|c|c|c|c|c|c|c|c|}
\hline \multirow{2}{*}{ Isotherms } & \multirow{2}{*}{ Constants } & \multicolumn{3}{|c|}{$\mathrm{Sb}(\mathrm{III})$} & \multicolumn{3}{|c|}{$\mathrm{Sb}(\mathrm{V})$} \\
\hline & & PFS & FC & $\mathrm{FeSO}_{4}$ & PFS & FC & $\mathrm{FeSO}_{4}$ \\
\hline \multirow[t]{3}{*}{ Freundlich } & $\begin{aligned} & \mathrm{K}_{\mathrm{F}} \\
\left(\left(\mathrm{mg} \cdot \mathrm{g}^{-1}\right)\right. & \left.\left(\mathrm{L} \cdot \mathrm{mg}^{-1}\right)^{-1 / \mathrm{n}}\right)\end{aligned}$ & 13.481 & 2.201 & 0.01 & 1.829 & 0.834 & 0.683 \\
\hline & $\mathrm{n}$ & 1.735 & 1.146 & 0.698 & 1.809 & 1.542 & 1.95 \\
\hline & $\mathrm{R}^{2}$ & 0.799 & 0.882 & 0.963 & 0.948 & 0.983 & 0.918 \\
\hline \multirow[t]{4}{*}{ Sips } & $\mathrm{Q}_{\mathrm{m}}\left(\mathrm{mg} \cdot \mathrm{g}^{-1}\right)$ & 350.56 & 356.05 & 60.84 & 264.39 & 306.04 & 43.29 \\
\hline & $\mathrm{K}_{\mathrm{s}}\left(\mathrm{L} \cdot \mathrm{mg}^{-1}\right)$ & $2.52 \times 10^{-8}$ & $4.54 \times 10^{-4}$ & $1.99 \times 10^{-5}$ & $2.29 \times 10^{-4}$ & $4.54 \times 10^{-5}$ & $1.99 \times 10^{-5}$ \\
\hline & $\gamma$ & 4.1263 & 0.923 & 1.676 & 1.103 & 0.923 & 1.677 \\
\hline & $\mathrm{R}^{2}$ & 0.974 & 0.976 & 0.99 & 0.970 & 0.983 & 0.995 \\
\hline
\end{tabular}

Figure 3a shows that with the increase of residual Sb concentration, the adsorption capacity increased until reaching an equilibrium. The fitted Sips isotherms revealed that the behavior of $\mathrm{Sb}$ adsorption was related to heterogeneous adsorption at low concentration but was similar to the homogenous adsorption at high concentration [26]. The maximum simulated adsorption capacity was $350 \mathrm{mg} \cdot \mathrm{g}^{-1}$ with PFS, $356 \mathrm{mg} \cdot \mathrm{g}^{-1}$ with FC, and $61 \mathrm{mg} \cdot \mathrm{g}^{-1}$ with $\mathrm{FeSO}_{4}$ for $\mathrm{Sb}(\mathrm{III})$, and $264 \mathrm{mg} \cdot \mathrm{g}^{-1}$ with PFS, $306 \mathrm{mg} \cdot \mathrm{g}^{-1}$ with $\mathrm{FC}$, and $43 \mathrm{mg} \cdot \mathrm{g}^{-1}$ with $\mathrm{FeSO}_{4}$ for $\mathrm{Sb}(\mathrm{V})$, which were higher than many other iron-based adsorbents $[27,28]$. It indicates that the coagulation is potential at removing $\mathrm{Sb}$ at high initial concentrations. As shown in Figure 3b, PFS and FC exhibited similar maximum adsorption behavior. The removal performance of $\mathrm{Sb}(\mathrm{V})$ with both PFS and FC was better than that with $\mathrm{FeSO}_{4}$. The adsorption capacities for $\mathrm{Sb}(\mathrm{V})$ with iron-based coagulants were much lower than those of $\mathrm{Sb}(\mathrm{III})$, and the equilibrium concentration of $\mathrm{Sb}$ was higher than that of $\mathrm{Sb}$ (III).

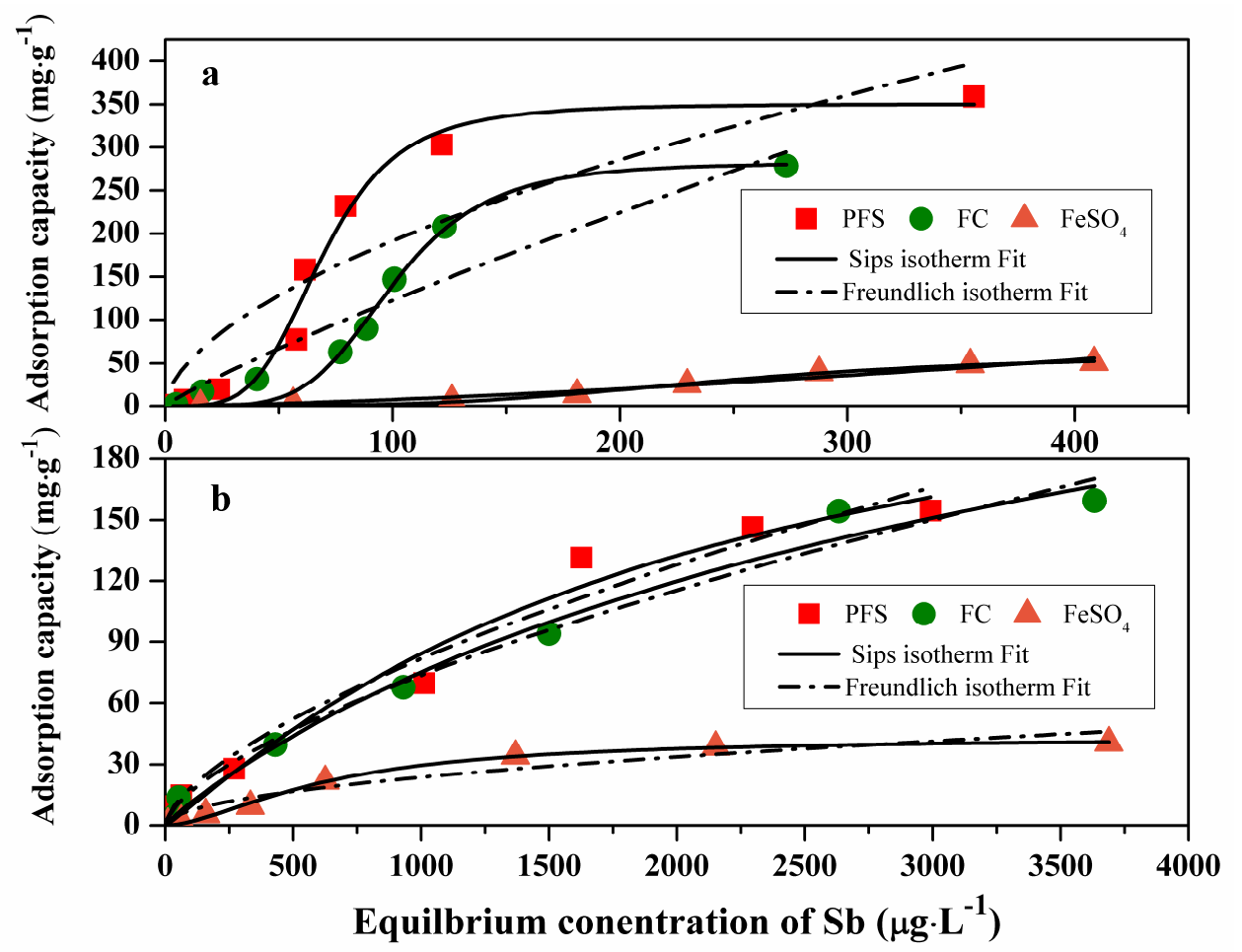

Figure 3. Coagulation of (a) $\mathrm{Sb}(\mathrm{III})$ and (b) $\mathrm{Sb}(\mathrm{V})$ by PFS, FC, and $\mathrm{FeSO}_{4}$ fitted with Freundlich and Sips isotherms (dosage of coagulants as Fe: $10 \mathrm{mg} \cdot \mathrm{L}^{-1}$ ). 


\subsection{Effects of Co-Existing Substances}

In a natural aqueous system, many constitutes may affect the removal of $\mathrm{Sb}$, such as $\mathrm{HA}$ and anions [16]. The HA is connected with many functional groups, such as carboxyl and hydroxyl groups, which commonly exist in the natural environment. Figure 4 shows the effects of $\mathrm{HA}, \mathrm{Cl}^{-}$, $\mathrm{F}^{-}, \mathrm{NO}_{3}{ }^{-}, \mathrm{HCO}_{3}{ }^{-}, \mathrm{SO}_{4}{ }^{2-}$, and $\mathrm{PO}_{4}{ }^{3-}$ on the removal of $\mathrm{Sb}$ by coagulation with FPS. In the presence of $\mathrm{Cl}^{-}, \mathrm{F}^{-}, \mathrm{NO}_{3}{ }^{-}$, and $\mathrm{SO}_{4}{ }^{2-}$, the effects on the removal rate of $\mathrm{Sb}$ by coagulation with $10 \mathrm{mg} \cdot \mathrm{L}^{-1}$ of PFS were negligible. With the presence of $\mathrm{HCO}_{3}{ }^{-}$, the removal rate of $\mathrm{Sb}(\mathrm{V})$ by coagulation was slightly decreased because the hydrolysis of $\mathrm{HCO}_{3}{ }^{-}$decreased the $\mathrm{pH}$ of the solution and affected the removal of $\mathrm{Sb}(\mathrm{V})$. However, with the presence of $\mathrm{PO}_{4}{ }^{3-}$, the removal of $\mathrm{Sb}(\mathrm{III})$ and $\mathrm{Sb}(\mathrm{V})$ was decreased remarkably, which was ascribed to the competition of adsorption sites between $\mathrm{Sb}$ and phosphate ions due to the similar tetrahedral structure and $\mathrm{s}^{2} \mathrm{p}^{3}$ outer electronic orbit [29]. HA also inhibited the removal of $\mathrm{Sb}(\mathrm{III})$ and $\mathrm{Sb}(\mathrm{V})$ remarkably. With the presence of $\mathrm{HA}$, the removal rates of $\mathrm{Sb}(\mathrm{III})$ by using PFS, FC, and $\mathrm{FeSO}_{4}$ decreased by $21.01 \%, 27.13 \%$, and $19.79 \%$, respectively, and those of $\mathrm{Sb}(\mathrm{V})$ decreased by $31.67 \%, 36.10 \%$, and $31.75 \%$ respectively. On the one hand, HA was competitive with Sb on the adsorption sites of coagulants. On the other hand, reactive functional groups of HA, such as phenolic and carboxylic acid, facilitated the combination of $\mathrm{Sb}$ and $\mathrm{HA}$, which increased the solubility of $\mathrm{Sb}$ and hence inhibited the removal of $\mathrm{Sb}[16,18]$.

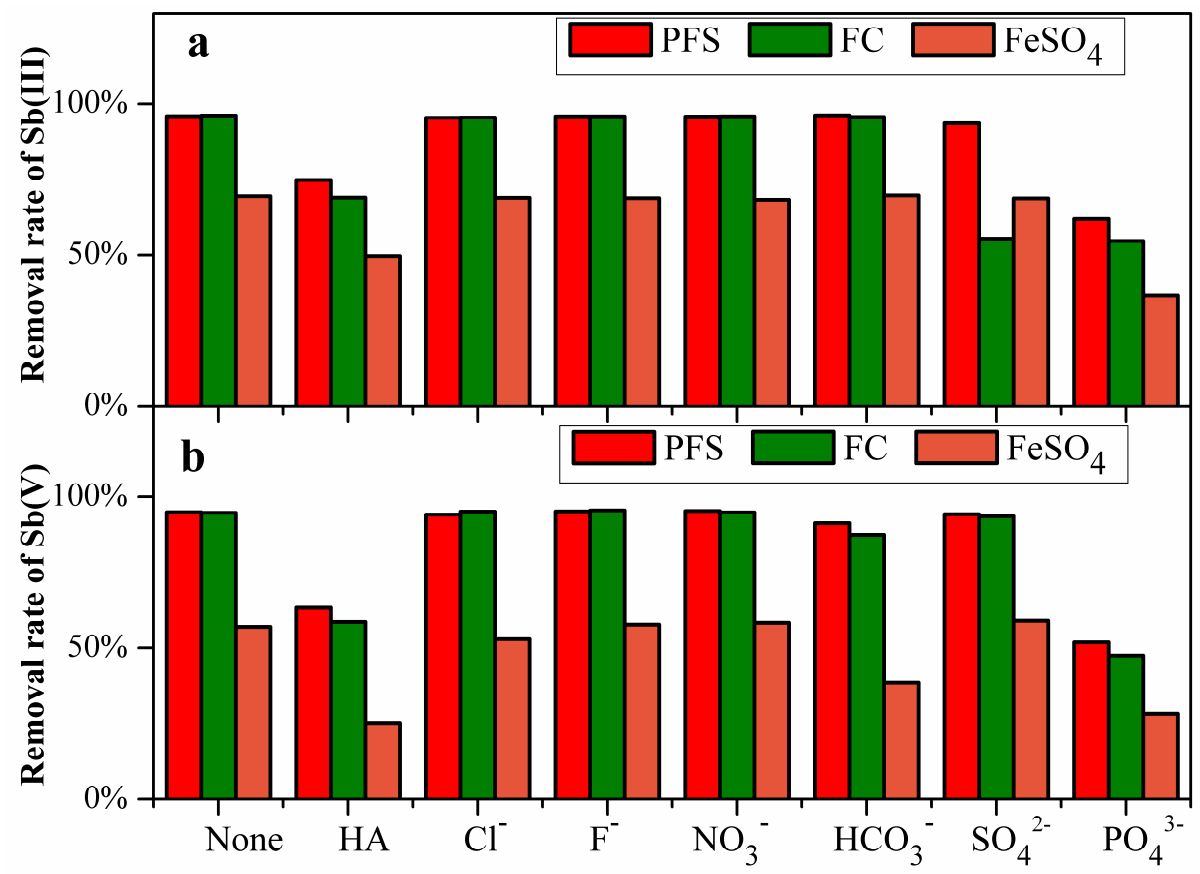

Co-existing substances

Figure 4. Effects of co-existing substances on the removal of (a) $\mathrm{Sb}$ (III) and (b) $\mathrm{Sb}(\mathrm{V})$ (the initial concentrations of $\mathrm{Sb}(\mathrm{III})$ and $\mathrm{Sb}(\mathrm{V}): 192$ and $205 \mu \mathrm{g} \cdot \mathrm{L}^{-1}$, respectively; dosage of PFS as Fe:10 $\mathrm{mg} \cdot \mathrm{L}^{-1}$ ).

\subsection{Effects of Oxidation on Sb Removal}

In a naturally aerobic environment, many oxidizing substances may oxidize $\mathrm{Sb}$ (III) to $\mathrm{Sb}(\mathrm{V})$, which affects the mobility and removal of $\mathrm{Sb}[25,30]$. In this study, the effects of $\mathrm{KMnO}_{4}$ and aeration on the removal of $\mathrm{Sb}$ by coagulation with PFS of $10 \mathrm{mg} \cdot \mathrm{L}^{-1}$ were investigated. Before coagulation, different concentrations of $\mathrm{KMnO}_{4}$ were applied for pre-oxidization, and the aeration process was conducted for different times.

Figure 5 a shows that the removal efficiency of $\mathrm{Sb}$ (III) decreased remarkably from $95 \%$ to $35 \%$ with the presence of $1 \mathrm{mg} \cdot \mathrm{L}^{-1} \mathrm{KMnO}_{4}$, which was ascribed to the oxidization of $\mathrm{Sb}$ (III) by $\mathrm{KMnO}_{4}$ and interference of $\mathrm{MnO}_{4}^{-}$on the competition for the adsorption sites. When the $\mathrm{KMnO}_{4}$ concentration 
was further increased, the removal rate reached a plateau. Additionally, the removal rate of $\mathrm{Sb}(\mathrm{V})$ with PFS coagulation decreased from $94 \%$ to $51 \%$ with the presence of $1 \mathrm{mg} \cdot \mathrm{L}^{-1} \mathrm{KMnO}_{4}$ and further decreased to $29 \%$ with the presence of $10 \mathrm{mg} \cdot \mathrm{L}^{-1} \mathrm{KMnO}_{4}$.
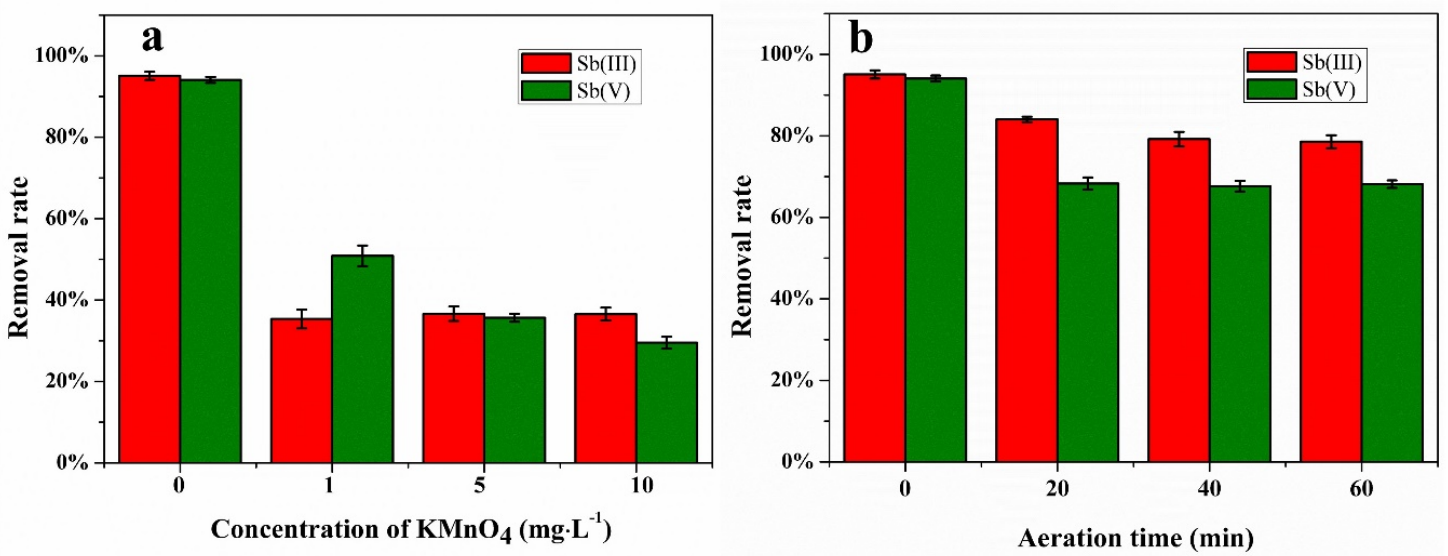

Figure 5. (a) Effects of the concentration of $\mathrm{KMnO}_{4}$ in oxidation on the removal of $\mathrm{Sb}$, and (b) effects of aeration time on the removal of $\mathrm{Sb}$ (the initial concentrations of $\mathrm{Sb}(\mathrm{III})$ and $\mathrm{Sb}(\mathrm{V}): 200 \mu \mathrm{g} \cdot \mathrm{L}^{-1}$; dosage of PFS as Fe:10 $\left.\mathrm{mg} \cdot \mathrm{L}^{-1}\right)$.

Figure $5 \mathrm{~b}$ shows that when the aeration time was increased from 0 min to $40 \mathrm{~min}$, the removal rate of $\mathrm{Sb}$ (III) decreased from $94 \%$ to $79 \%$. However, when the aeration time was further increased, the reduction in the $\mathrm{Sb}(\mathrm{III})$ removal rate was negligible. The removal rate of $\mathrm{Sb}(\mathrm{V})$ also decreased by $36 \%$ with aeration for $60 \mathrm{~min}$. Besides the oxidation role of aeration, the decrease in $\mathrm{Sb}$ removal rate was ascribed to formed bubbles having affected the characteristics and affinity of the flocs, thereby inhibiting the adsorption of $\mathrm{Sb}$ onto the flocs [25].

\subsection{Mechanisms}

There were many possible mechanisms for the removal of $\mathrm{Sb}(\mathrm{III})$ and $\mathrm{Sb}(\mathrm{V})$ with iron-based coagulants, such as adsorption, precipitation, and coprecipitation. However, previous studies have demonstrated that precipitation and coprecipitation were negligible, which was in accord with our results $[18,19]$. Thereby, we attributed the removal of $\mathrm{Sb}$ by coagulation to the adsorption of HFO flocs, and we analyzed the mechanism and function of adsorption onto formed HFO flocs in the removal of $\mathrm{Sb}$.

The combination of in situ formed $\mathrm{HFO}$ and $\mathrm{Sb}(\mathrm{III})$ or $\mathrm{Sb}(\mathrm{V})$ was investigated via FTIR spectra analysis (Figure 6). The spectral bands that appeared at around 3509 and $1641 \mathrm{~cm}^{-1}$ were attributed to the stretching and bending vibrations of -OH groups, respectively, for the adsorption of water on the surface of precipitates [31]. Peaks at $1402 \mathrm{~cm}^{-1}$ were ascribed to the bending vibrations of $-\mathrm{OH}$ groups connected to $\mathrm{Sb}$ and iron [32]. Peaks near $646 \mathrm{~cm}^{-1}$ were assigned to the $\mathrm{Fe}-\mathrm{OH}$ bonds of precipitates, and the small shift of those bands was attributed to the adsorption of $\mathrm{Sb}(\mathrm{III})$ and $\mathrm{Sb}(\mathrm{V})$ [33]. The small peaks at 590 and $487 \mathrm{~cm}^{-1}$ of $\mathrm{HFO}-\mathrm{Sb}(\mathrm{V})$, which were observed for the precipitates produced by coagulation of $\mathrm{Sb}(\mathrm{V})$ with PFS and FC, were due to the symmetric stretching and bending vibrations of $\mathrm{Sb}(\mathrm{V})-\mathrm{O}$ bonds, respectively [32]. In addition, the $\mathrm{Sb}(\mathrm{V})-\mathrm{O}$ bonds did not appear in the spectrum of precipitates produced by the coagulation of $\mathrm{Sb}(\mathrm{III})$, which indicates that no oxidation of $\mathrm{Sb}$ (III) appeared on the surface of iron hydrolytic precipitates. 


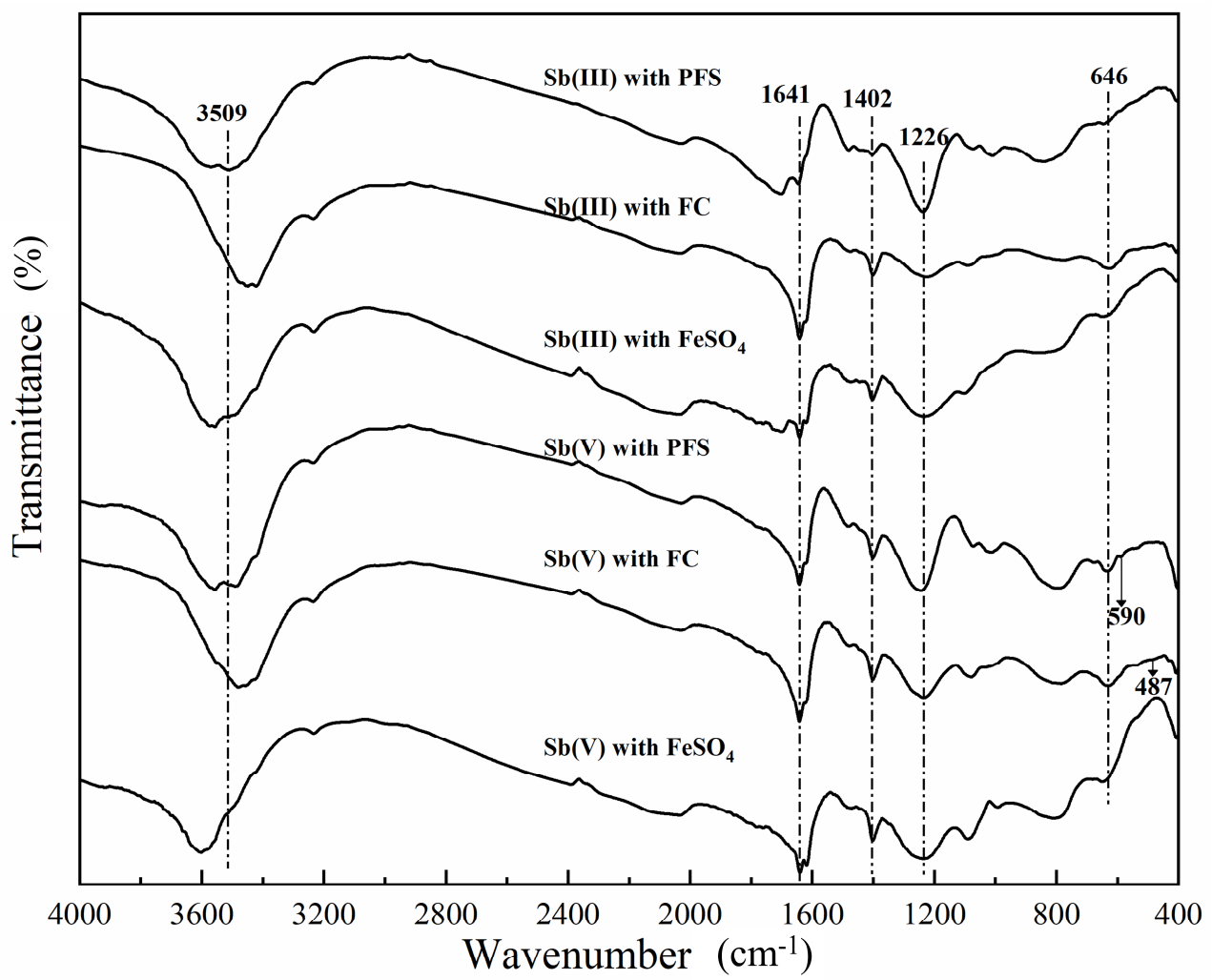

Figure 6. FTIR spectra for the precipitates of PFS, $\mathrm{FC}$, and $\mathrm{FeSO}_{4}$ after reaction with $\mathrm{Sb}(\mathrm{III})$ and $\mathrm{Sb}(\mathrm{V})$.

The in situ formed HFO by iron-based coagulation was highly active, but it was also unstable and easy to turn into ferric hydroxide precipitation of low activity. PFS, with the molecular formula of $\left(\mathrm{Fe}_{2}(\mathrm{OH})_{\mathrm{n}}\left(\mathrm{SO}_{4}\right)_{3-\mathrm{n} / 2}\right)_{\mathrm{m}}$, was much more complex than $\mathrm{FC}\left(\mathrm{FeCl}_{3}\right)$. The hydrolyzed and polymerized iron ions in the aqueous solution formed more stable HFO flocs, and the addition of hydroxyl content facilitated the chemical bonding between $\mathrm{HFO}$ flocs and $\mathrm{Sb}$. In the coagulation process with $\mathrm{FeSO}_{4}$, flocs formed by the hydrolysis of $\mathrm{Fe}^{2+}$ ions were simple mononuclear complex, and their adsorption capacity was poorer than that of flocs formed by the hydrolysis of PFS and FC. In addition, the electrostatic interaction between the positive $\mathrm{HFO}$ flocs and negative $\mathrm{Sb}(\mathrm{OH})_{6}{ }^{-}$facilitated the removal of $\mathrm{Sb}(\mathrm{V})$.

\section{Conclusions}

The performance of $\mathrm{Fe}(\mathrm{III})$-based (PFS, FC) and $\mathrm{Fe}(\mathrm{II})$-based $\left(\mathrm{FeSO}_{4}\right)$ coagulants on the removal of $\mathrm{Sb}(\mathrm{III})$ and $\mathrm{Sb}(\mathrm{V})$ was investigated. The removal efficiency of $\mathrm{Fe}(\mathrm{III})$-based coagulants (PFS and FC) was higher than that of the $\mathrm{Fe}(\mathrm{II})$-based coagulant $\left(\mathrm{FeSO}_{4}\right)$. At the optimum $\mathrm{pH}$ of 5 , by using $\mathrm{Fe}(\mathrm{III})$-based salts with coagulant dose of $10 \mathrm{mg} \cdot \mathrm{L}^{-1}$ at the initial Sb loading of $200 \mu \mathrm{g} \cdot \mathrm{L}^{-1}$, the removal rate of $\mathrm{Sb}$ (III) (97\% with PFS and $98 \%$ with FC) was higher than that of $\mathrm{Sb}(\mathrm{V})(91 \%$ with $\mathrm{PFS}$ and $93 \%$ with FC), but the opposite was true with Fe(II)-based salts, wherein $61 \%$ of $\mathrm{Sb}(\mathrm{III})$ and $76 \%$ of $\mathrm{Sb}(\mathrm{V})$ were removed. The adsorption capacities by using PFS, $\mathrm{FC}$, and $\mathrm{FeSO}_{4}$ fit the Sips adsorption isotherms well, and the simulated maximum adsorption capacities were $350 \mathrm{mg} \cdot \mathrm{g}^{-1}$ for Sb(III) and $264 \mathrm{mg} \cdot \mathrm{g}^{-1}$ for $\mathrm{Sb}(\mathrm{V})$ by coagulation with PFS. The results indicated that the removal of $\mathrm{Sb}$ was attributed to the heterogenous adsorption of HFO at low initial Sb loadings, which was supported by the results of FTIR spectrum analysis. Oxidation inhibited the removal of $\mathrm{Sb}$ (III) remarkably. $\mathrm{KMnO}_{4}$, with its strong oxidizing property, remarkably decreased the removal efficiency of $\mathrm{Sb}$. Moreover, the aeration process reduced the removal rate of $\mathrm{Sb}$. In practical applications, $\mathrm{Fe}(\mathrm{III})$-based coagulants have great potential in the treatment of $\mathrm{Sb}$ contaminations in rivers or lakes due to their effective and efficient performance, as well as advantages of conveniences and low cost. Furthermore, the oxidation process could be avoided in the removal of $\mathrm{Sb}(\mathrm{III})$. 
Supplementary Materials: The following are available online at http://www.mdpi.com/2073-4441/12/1/66/s1: Figure S1: Removal of Sb from Taihu lake water by coagulation using PFS (initial concentration of $\mathrm{Sb}(\mathrm{III})$ : $\left.104 \mu \mathrm{g} \cdot \mathrm{L}^{-1} ; \mathrm{Sb}(\mathrm{V}): 116 \mu \mathrm{g} \cdot \mathrm{L}^{-1}\right)$.

Author Contributions: K.C. conducted the experiments and wrote the original manuscript; H.W. and J.L. improved the manuscript; F.L. supervised the experiments. All authors have read and agreed to the published version of the manuscript.

Funding: This research was supported by the National Natural Science Foundation of China (21777119) and the Foundation of State Key Laboratory of Pollution Control and Resource Reuse (Tongji University) (PCRRY15007).

Acknowledgments: We thank all anonymous reviewers and the editor for their insightful comments and suggestions.

Conflicts of Interest: The authors declare no conflict of interest.

\section{References}

1. He, M.; Wang, X.; Wu, F.; Fu, Z. Antimony pollution in China. Sci. Total Environ. 2012, 421-422, 41-50. [CrossRef] [PubMed]

2. Filella, M.; Belzile, N.; Chen, Y.W. Antimony in the environment: A review focused on natural waters II. Relevant solution chemistry. Earth-Sci. Rev. 2002, 59, 265-285. [CrossRef]

3. WHO. Guidelines for Drinking-water Quality. Organization, W.H., ed.; World Health Organization: Geneva, Switzerland, 2004.

4. USEPA. Water Related Fate of the 129 Priority Pollutants; USEPA: Washington, DC, USA, 1979; Volume 1.

5. EU. Council Directive 76/464/EEC of 4 May 1976 on Pollution Caused by Certain Dangerous Substances Discharged Into the Aquatic Environment of the Community. Off. J. L. 1976, 129, 23-29.

6. Mitrakas, M.; Mantha, Z.; Tzollas, N.; Stylianou, S.; Katsoyiannis, I.; Zouboulis, A. Removal of Antimony Species, $\mathrm{Sb}(\mathrm{III}) / \mathrm{Sb}(\mathrm{V})$, from Water by Using Iron Coagulants. Water 2018, 10, 1328. [CrossRef]

7. Wu, Z.; He, M.; Guo, X.; Zhou, R. Removal of antimony (III) and antimony (V) from drinking water by ferric chloride coagulation: Competing ion effect and the mechanism analysis. Sep. Purif. Technol. 2010, 76, 184-190. [CrossRef]

8. Fan, H.-T.; Sun, W.; Jiang, B.; Wang, Q.-J.; Li, D.-W.; Huang, C.-C.; Wang, K.-J.; Zhang, Z.-G.; Li, W.-X. Adsorption of antimony(III) from aqueous solution by mercapto-functionalized silica-supported organic-inorganic hybrid sorbent: Mechanism insights. Chem. Eng. J. 2016, 286, 128-138. [CrossRef]

9. Leng, Y.; Guo, W.; Su, S.; Yi, C.; Xing, L. Removal of antimony(III) from aqueous solution by graphene as an adsorbent. Chem. Eng. J. 2012, 211, 406-411. [CrossRef]

10. Du, X.; Qu, F.; Liang, H.; Li, K.; Yu, H.; Bai, L.; Li, G. Removal of antimony (III) from polluted surface water using a hybrid coagulation-flocculation-ultrafiltration (CF-UF) process. Chem. Eng. J. 2014, 254, $293-301$. [CrossRef]

11. Cao, D.; Zeng, H.; Yang, B.; Zhao, X. Mn assisted electrochemical generation of two-dimensional Fe-Mn layered double hydroxides for efficient $\mathrm{Sb}(\mathrm{V})$ removal. J. Hazard. Mater. 2017, 336, 33-40. [CrossRef]

12. Ungureanu, G.; Santos, S.; Boaventura, R.; Botelho, C. Arsenic and antimony in water and wastewater: Overview of removal techniques with special reference to latest advances in adsorption. J. Environ. Manag. 2015, 151, 326-342. [CrossRef]

13. Palmer, K.; Ronkanen, A.-K.; Klove, B. Efficient removal of arsenic, antimony and nickel from mine wastewaters in Northern treatment peatlands and potential risks in their long-term use. Ecol. Eng. 2015, 75, 350-364. [CrossRef]

14. Besold, J.; Eberle, A.; Noel, V.; Kujala, K.; Kumar, N.; Scheinost, A.C.; Pacheco, J.L.; Fendorf, S.; Planer-Friedrich, B. Antimonite Binding to Natural Organic Matter: Spectroscopic Evidence from a Mine Water Impacted Peatland. Environ. Sci.Technol. 2019, 53, 10792-10802. [CrossRef] [PubMed]

15. Gao, F.; Tang, X.; Yi, H.; Li, J.; Zhao, S.; Wang, J.; Chu, C.; Li, C. Promotional mechanisms of activity and $\mathrm{SO}_{2}$ tolerance of $\mathrm{Co}$ - or Ni-doped $\mathrm{MnOx}-\mathrm{CeO}_{2}$ catalysts for SCR of $\mathrm{NOx}$ with $\mathrm{NH} 3$ at low temperature. Chem. Eng. J. 2017, 317, 20-31. [CrossRef]

16. Watson, M.A.; Tubic, A.; Agbaba, J.; Nikic, J.; Maletic, S.; Jazic, J.M.; Dalmacija, B. Response surface methodology investigation into the interactions between arsenic and humic acid in water during the coagulation process. J. Hazard. Mater. 2016, 312, 150-158. [CrossRef] [PubMed] 
17. Kang, M.; Kamei, T.; Magara, Y. Comparing polyaluminum chloride and ferric chloride for antimony removal. Water Res. 2003, 37, 4171-4179. [CrossRef]

18. Guo, X.; Wu, Z.; He, M. Removal of antimony(V) and antimony(III) from drinking water by coagulation-flocculation-sedimentation (CFS). Water Res. 2009, 43, 4327-4335. [CrossRef] [PubMed]

19. Guo, W.; Fu, Z.; Wang, H.; Liu, S.; Wu, F.; Giesy, J.P. Removal of antimonate (Sb(V)) and antimonite (Sb(III)) from aqueous solutions by coagulation-flocculation-sedimentation (CFS): Dependence on influencing factors and insights into removal mechanisms. Sci. Total Environ. 2018, 644, 1277-1285. [CrossRef]

20. Filella, M.; Belzile, N.; Chen, Y.W. Antimony in the environment: A review focused on natural waters I. Occurrence. Earth-Sci. Rev. 2002, 57, 125-176. [CrossRef]

21. Vink, B.W. Stability relations of antimony and arsenic compounds in the light of revised and extended Eh-pH diagrams. Chem. Geol. 1996, 130, 21-30. [CrossRef]

22. Mitsunobu, S.; Harada, T.; Takahashi, Y. Comparison of antimony behavior with that of arsenic under various soil redox conditions. Environ. Sci. Technol. 2006, 40, 7270-7276. [CrossRef]

23. Wilson, S.C.; Lockwood, P.V.; Ashley, P.M.; Tighe, M. The chemistry and behaviour of antimony in the soil environment with comparisons to arsenic: A critical review. Environ. Pollut. 2010, 158, 1169-1181. [CrossRef] [PubMed]

24. Sun, Q.; Liu, C.; Alves, M.E.; Ata-Ul-Karim, S.T.; Zhou, D.-M.; He, J.-Z.; Cui, P.-X.; Wang, Y.-J. The oxidation and sorption mechanism of $\mathrm{Sb}$ on delta-MnO2. Chem. Eng. J. 2018, 342, 429-437. [CrossRef]

25. Leuz, A.K.; Hug, S.J.; Wehrli, B.; Johnson, C.A. Iron-mediated oxidation of antimony(III) by oxygen and hydrogen peroxide compared to arsenic(III) oxidation. Environ. Sci. Technol. 2006, 40, 2565-2571. [CrossRef] [PubMed]

26. Vijayaraghavan, K.; Padmesh, T.V.N.; Palanivelu, K.; Velan, M. Biosorption of nickel(II) ions onto Sargassum wightii: Application of two-parameter and three-parameter isotherm models. J. Hazard. Mater. 2006, 133, 304-308. [CrossRef] [PubMed]

27. Qi, P.; Pichler, T. Competitive adsorption of $\mathrm{As}(\mathrm{III}), \mathrm{As}(\mathrm{V}), \mathrm{Sb}(\mathrm{III})$ and $\mathrm{Sb}(\mathrm{V})$ onto ferrihydrite in multi-component systems: Implications for mobility and distribution. J. Hazard. Mater. 2017, 330, 142-148. [CrossRef]

28. Li, J.; Zheng, B.; He, Y.; Zhou, Y.; Chen, X.; Ruan, S.; Yang, Y.; Dai, C.; Tang, L. Antimony contamination, consequences and removal techniques: A review. Ecotoxicol. Environ. Saf. 2018, 156, 125-134. [CrossRef]

29. Lu, H.; Zhu, Z.; Zhang, H.; Zhu, J.; Qiu, Y. Simultaneous removal of arsenate and antimonate in simulated and practical water samples by adsorption onto Zn/Fe layered double hydroxide. Chem. Eng. J. 2015, 276, 365-375. [CrossRef]

30. Cai, Y.; Mi, Y.; Zhang, H. Kinetic modeling of antimony(III) oxidation and sorption in soils. J. Hazard. Mater. 2016, 316, 102-109. [CrossRef]

31. Fan, H.-T.; Tang, Q.; Sun, Y.; Zhang, Z.-G.; Li, W.-X. Selective removal of antimony(III) from aqueous solution using antimony(III)-imprinted organic-inorganic hybrid sorbents by combination of surface imprinting technique with sol-gel process. Chem. Eng. J. 2014, 258, 146-156. [CrossRef]

32. Liu, R.; Liu, F.; Hu, C.; He, Z.; Liu, H.; Qu, J. Simultaneous removal of Cd(II) and Sb(V) by Fe-Mn binary oxide: Positive effects of $\mathrm{Cd}(\mathrm{II})$ on $\mathrm{Sb}(\mathrm{V})$ adsorption. J. Hazard. Mater. 2015, 300, 847-854. [CrossRef]

33. Lan, B.; Wang, Y.; Wang, X.; Zhou, X.; Kang, Y.; Li, L. Aqueous arsenic (As) and antimony (Sb) removal by potassium ferrate. Chem. Eng. J. 2016, 292, 389-397. [CrossRef]

(C) 2019 by the authors. Licensee MDPI, Basel, Switzerland. This article is an open access article distributed under the terms and conditions of the Creative Commons Attribution (CC BY) license (http://creativecommons.org/licenses/by/4.0/). 